\title{
Melatonin inhibits triple-negative breast cancer progression through the Lnc049808-FUNDC1 pathway
}

\author{
Anli Yang ${ }^{1,5}{ }^{1,5}$, Fu Peng
Yanan Kong
${ }^{1 凶}$
} (c) The Author(s) 2021

Melatonin has been reported to have tumor-suppressive effects via comprehensive molecular mechanisms, and long non-coding RNAs (IncRNAs) may participate in this process. However, the mechanism by which melatonin affects the function of IncRNAs in triple-negative breast cancer (TNBC), the most aggressive subtype of breast cancer, is still unknown. Therefore, we aimed to investigate the differentially expressed mRNAs and IncRNAs in melatonin-treated TNBC cells and the interaction mechanisms. Microarray analyses were performed to identify differentially expressed mRNAs and IncRNAs in TNBC cell lines after melatonin treatment. To explore the functions and underlying mechanisms of the mRNAs and IncRNAs candidates, a series of in vitro experiments were conducted, including CCK-8, Transwell, colony formation, luciferase reporter gene, and RNA immunoprecipitation (RIP) assays, and mouse xenograft models were established. We found that after melatonin treatment, FUNDC1 and Inc049808 downregulated in TNBC cell lines. Knockdown of FUNDC1 and Inc049808 inhibited TNBC cell proliferation, invasion, and metastasis. Moreover, Inc049808 and FUNDC1 acted as competing endogenous RNAs (ceRNAs) for binding to miR-101. These findings indicated that melatonin inhibited TNBC progression through the Inc049808-FUNDC1 pathway and melatonin could be used as a potential therapeutic agent for TNBC.

Cell Death and Disease (2021)12:712; https://doi.org/10.1038/s41419-021-04006-x

\section{INTRODUCTION}

Triple-negative breast cancer (TNBC) accounts for $15-20 \%$ of all breast cancers, and compared with other subtypes, it exhibits more aggressive biological behaviors and worse clinical outcomes due to the lack of efficient molecular targets [1]. Melatonin (N-acetyl-5methoxytryptamine) is a natural indoleamine, which is mainly produced by the pineal gland in humans and other animals in response to darkness and light [2,3]. Studies have shown that in addition to circadian rhythm monitoring, melatonin also has antiinflammatory, antioxidant, immunomodulatory, vascular regulation, and anticancer activities [4-7]. The anticancer properties of melatonin are mediated via suppression of tumor metabolism and critical signaling pathways, including PI3K/Akt, NF-kB, hypoxiainducible factor-1 (HIF-1), cyclin-dependent kinase (CDKs), insulinlike growth factor receptor (IGF-1R), and estrogen receptor signaling [8-10]. A series of studies indicated that melatonin suppressed ERa mRNA expression, inhibited p38 MAPK signaling, repressed epithelial-to-mesenchymal transition, and correlated with intrinsic resistance to tamoxifen and doxorubicin in estrogen receptor alpha (ERa)-positive human breast cancer [11, 12]. However, the role of melatonin in TNBC remains controversial. Specifically, it is unclear how long noncoding RNAs (IncRNAs) are involved in regulating TNBC.
LncRNAs, more than 200 nucleotides, are a type of transcript without protein translation. It has been proven that they play oncogenic or tumor-suppressive roles in various malignancies and are involved in the progression of breast cancer [13-15]. However, whether melatonin affects IncRNA expression and the mechanisms underlying the effects of melatonin in TNBC remain unknown. Therefore, our study aims to explore the expression profiles of mRNAs and IncRNAs in melatonin-treated TNBC cells by wholegenome mRNA and IncRNA expression microarray analyses. Moreover, a series of in vitro and in vivo experiments were conducted to further explore the roles and mechanisms of the screened differentially expressed mRNAs and IncRNAs in TNBC. Our results revealed that FUNDC1, a highly conserved mitochondrial outer membrane protein that plays an important role in mitochondrial autophagy, and the Inc049808 (NONMMUT049808) significantly downregulated in TNBC cell lines that were pretreated with melatonin. Knockdown of FUNDC1 and Inc049808 suppressed TNBC cell proliferation, invasion, and metastasis. Functional assays showed that Inc049808 and FUNDC1 acted as competing endogenous RNAs (ceRNAs) for binding to miR-101. Our findings indicated that melatonin inhibited TNBC progression through the Inc049808-FUNDC1 pathway and that melatonin could be used as a potential therapeutic agent for TNBC.

\footnotetext{
${ }^{1}$ Sun Yat-sen University Cancer Center, State Key Laboratory of Oncology in South China, Collaborative Innovation Center for Cancer Medicine, Guangzhou, P. R. China. ${ }^{2}$ Key

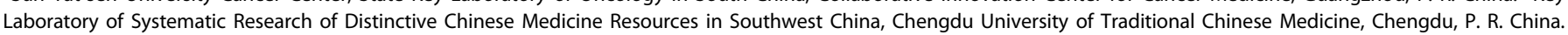

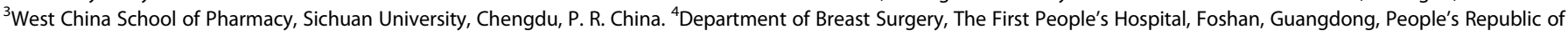
China. ${ }^{5}$ These authors contributed equally: Anli Yang, Fu Peng, Lewei Zhu. ${ }^{凶}$ email: pengchengchengdu@126.com; liupeng@sysucc.org.cn; kongyn@sysucc.org.cn Edited by A. Stephanou
} 


\section{RESULTS}

FUNDC1 knockdown inhibited TNBC progression

To validate the effect of melatonin on TNBC, 4T1, 891, and BT549 TNBC cells were treated with melatonin $(10-1000 \mathrm{nM})$ or the vehicle for 48 or $96 \mathrm{~h}$ (Fig. 1A). We found that melatonin inhibits TNBC cell proliferation in a dose- and time-dependent manner. To reveal the underlying mechanism, whole-genome mRNA expression microarray analyses were performed in melatonin-untreated and melatonin-treated $4 \mathrm{~T} 1$ and 891 cells. The top 33 differentially expressed mRNAs are shown in Fig. 1B. Among these mRNAs, FUNDC1 was upregulated in the melatonin-treated cells, which was a highly conserved mitochondrial outer membrane protein and played an important role in mitochondrial autophagy. However, the expression and function of FUNDC1 are unknown in TNBC. According to the TCGA database, FUNDC1 was increased in TNBC tissues compared to normal tissues (Fig. 1C). We further confirmed that the expression levels of FUNDC1 upregulated in breast cancer cell lines (Fig. 1D). To explore the function of FUNDC1 in the progression of TNBC, we used short hairpin RNA (shRNA) to knock down FUNDC1 expression. Three candidate shRNAs were constructed, and their knockdown efficiency was validated. We found that sh-FUNDC1\#2 produced the strongest inhibition, and this shRNA was selected for use in the following experiments (Fig. 1E). The Cell Counting Kit-8 (CCK-8) assay revealed significant inhibition of cell proliferation by FUNDC1 knockdown (Fig. 1F). FUNDC1 knockdown also weakened the cell colony formation ability (Fig. 1G). Transwell assay showed that FUNDC1 knockdown suppressed cell invasion (Fig. 1H). To further confirm the function of FUNDC1 in vivo, we established mouse xenograft models and found that FUNDC1 knockdown significantly suppressed tumor growth (Fig. 1I) and lung metastasis (Fig. $1 \mathrm{~J})$. Our findings demonstrated that FUNDC1 knockdown inhibited TNBC progression.

\section{FUNDC1 is a target gene regulated by miR-101}

To figure out the potential microRNAs (miRNAs) that may regulate FUNDC1, we searched the TargetScan, and miR-101 was predicted (Fig. 2A). MiR-101 serves as a tumor suppressor and participate in multiple cancer-related biological processes, including proliferation, apoptosis, angiogenesis, drug resistance, invasion, and metastasis. To validate our bioinformatics prediction, we measured the expression levels of miR-101 and found it was downregulated in TNBC cell lines (Fig. 2B). Consistently, the hsa-miR-101 was also downregulated in TNBC tissues compared to normal tissues, according to the TCGA database (Fig. 2C). Besides, we observed that FUNDC1 was downregulated by miR-101 but upregulated by locked nucleic acid (LNA)-miR-101 (Fig. 2D). A luciferase reporter assay was performed to confirm the direct binding between FUNDC1 and miR-101. We found that the luciferase activity significantly decreased with the transfection of wild-type (WT) luciferase vector. However, no similar effect was observed with the transfection of mutant vector (Fig. 2E). These results suggested that FUNDC1 is a target gene regulated by miR-101. The CCK-8 assay revealed that miR-101 suppression reversed the inhibition of cell proliferation induced by FUNDC1 knockdown (Fig. 2F). MiR101 suppression also reversed the decrease in the cell colony formation ability induced by FUNDC1 knockdown (Fig. 2G). The Transwell assay showed that miR-101 suppression reversed the increase in apoptosis and the decrease in cell invasion induced by FUNDC1 knockdown (Fig. 2H). The mouse xenograft experiments showed that the suppression of tumor growth (Fig. 2l) and lung metastasis (Fig. 2J) induced by FUNDC1 knockdown was also reversed by miR-101 suppression. These findings prove that FUNDC1 is a target gene regulated by miR-101.

\section{Lnc049808 knockdown inhibited TNBC progression}

LncRNA microarray analyses were performed with 4T1 and 891 TNBC cells pretreated with melatonin. The results showed that 40
IncRNAs downregulated at least twofold (Fig. 3A). Among these 40 IncRNAs, we validated the expression levels of the top five downregulated IncRNAs and found that NONMMUT049808 was the sharpest drop after melatonin treatment (Fig. 3B). Thus, we named this IncRNA Inc049808 and aimed to study it through a series of experiments. shRNA was used to knock down Inc049808 to explore the function of Inc049808 in TNBC progression, and sh049808\#1 produced the highest suppression efficiency and was adopted in subsequent experiments (Fig. 3C). The CCK-8 assay revealed significant inhibition of cell proliferation by Inc049808 knockdown (Fig. 3D). Inc049808 knockdown also weakened the cell colony formation ability (Fig. 3E). The Transwell assay showed that Inc049808 knockdown suppressed cell invasion (Fig. 3F). To further confirm the role of Inc049808 in vivo, mouse xenograft models were established, and significant inhibition of tumor growth (Fig. 3G) and lung metastasis by Inc049808 knockdown was observed (Fig. 3H). Our results showed that Inc049808 knockdown inhibited TNBC progression.

\section{Lnc049808 is a target of miR-101}

To explore the intracellular localization of Inc049808, we detected the expression of Inc049808 and found that Inc049808 was mainly localized in the cytoplasm (Fig. 4A). Via bioinformatic analysis, we found that Inc049808 contains sequences complementary to miR101 (Fig. 4B). Next, we performed an RNA immunoprecipitation (RIP) assay and found that miR-101 could bind to Inc049808 (Fig. 4C). Furthermore, by conducting a luciferase reporter assay, decreased luciferase activity was observed after transfection with miR-101 (Fig. 4D), suggesting that Inc049808 is a target of miR101. The CCK-8 assay revealed that miR-101 suppression reversed the inhibition of cell proliferation induced by knockdown of Inc049808 (Fig. 4E). MiR-101 suppression also reversed the decrease in the cell colony formation ability induced by Inc049808 knockdown (Fig. 4F). The Transwell assay showed that miR-101 suppression reversed the increase in apoptosis and the decrease in cell invasion induced by Inc049808 knockdown (Fig. 4G). The mouse xenograft experiments showed that the reduction in tumor growth (Fig. 4H) and lung metastasis (Fig. 4l) induced by Inc049808 knockdown could be reversed by miR-101 suppression. These findings proved that Inc049808 is a target of miR-101 and that miR-101 regulates the function of Inc049808.

Lnc049808 and FUNDC1 function as ceRNAs to regulate miR101

To explore the relationship among Inc049808, FUNDC1, and miR101, we performed an Ago2 RIP assay and found that Inc049808, FUNDC1, and miR-101 were mainly enriched in the Ago2 precipitate (Fig. 5A). Furthermore, Inc049808 knockdown reduced the enrichment of Inc049808 on Ago2 but enhanced the enrichment of FUNDC1 on Ago2 (Fig. 5B). FUNDC1 knockdown reduced the enrichment of FUNDC1 on Ago2 but enhanced the enrichment of Inc049808 on Ago2 (Fig. 5C). These results suggested that Inc049808 and FUNDC1 can act as ceRNAs and compete for binding to miRNAs. The regulation of Inc049808, FUNDC1, and miR-101 was further confirmed, and we found that Inc049808 knockdown decreased FUNDC1 expression but LNA-miR-101 reversed the expression of FUNDC1 (Fig. 5D). We also observed decreased expression of Inc049808 when FUNDC1 was knocked down but increased expression of Inc049808 when miR-101 was inhibited (Fig. 5E). These data suggested that Inc049808 and FUNDC1 function as ceRNAs for miR-101 in regulating TNBC progression.

\section{DISCUSSION}

Melatonin has been reported to have anticancer effects via comprehensive molecular mechanisms, and IncRNAs may participate in this process. In this study, whole-genome mRNA and IncRNA expression microarray analyses were performed in melatonin-treated 
A
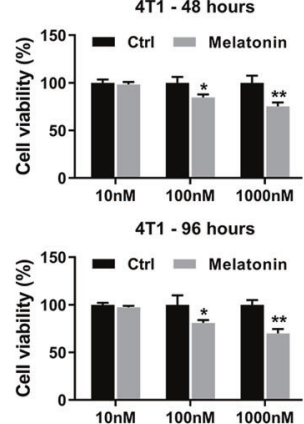

C

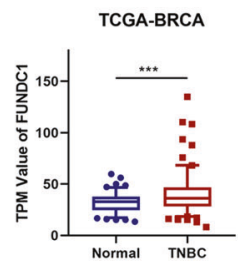

891 - 48 hours

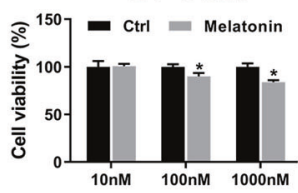

891 - 96 hours

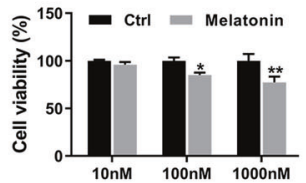

D

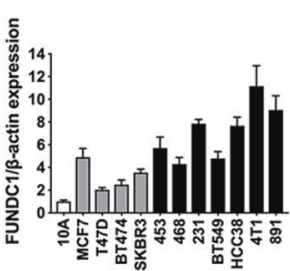

BT549 - 48 hours

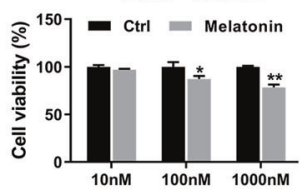

BT549 - 96 hours

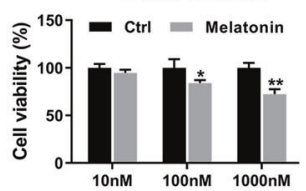

E

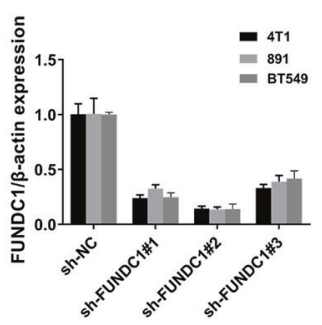

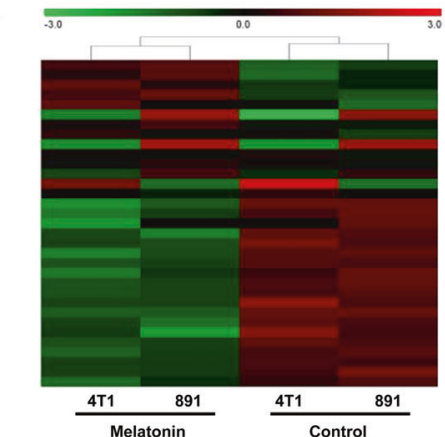

F

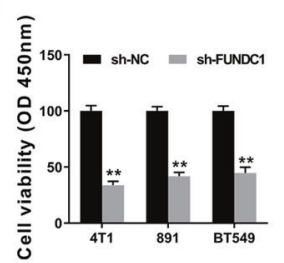

G
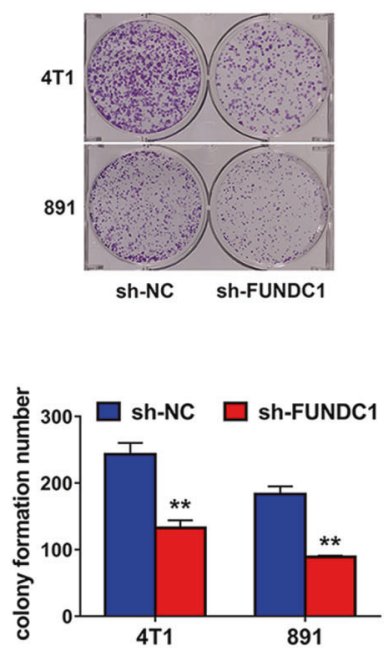

H
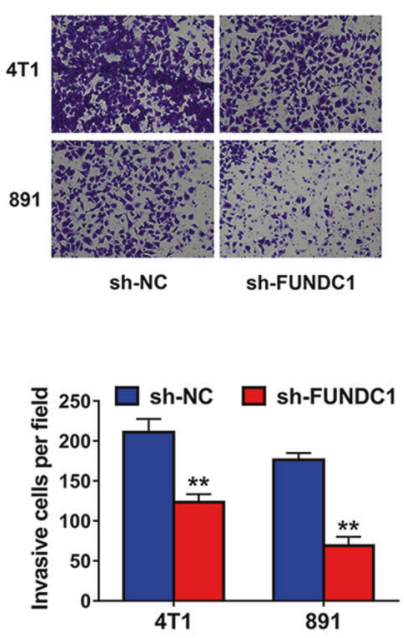

I
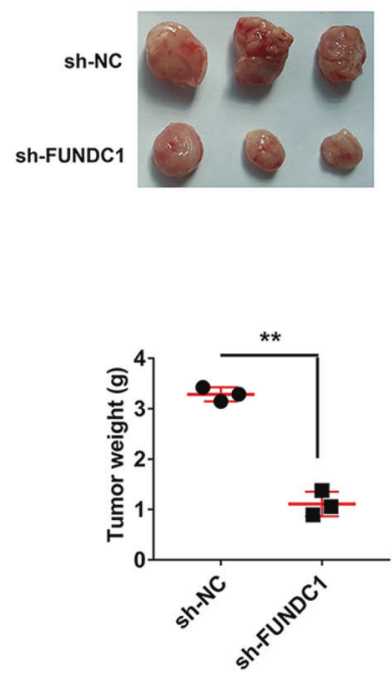

J
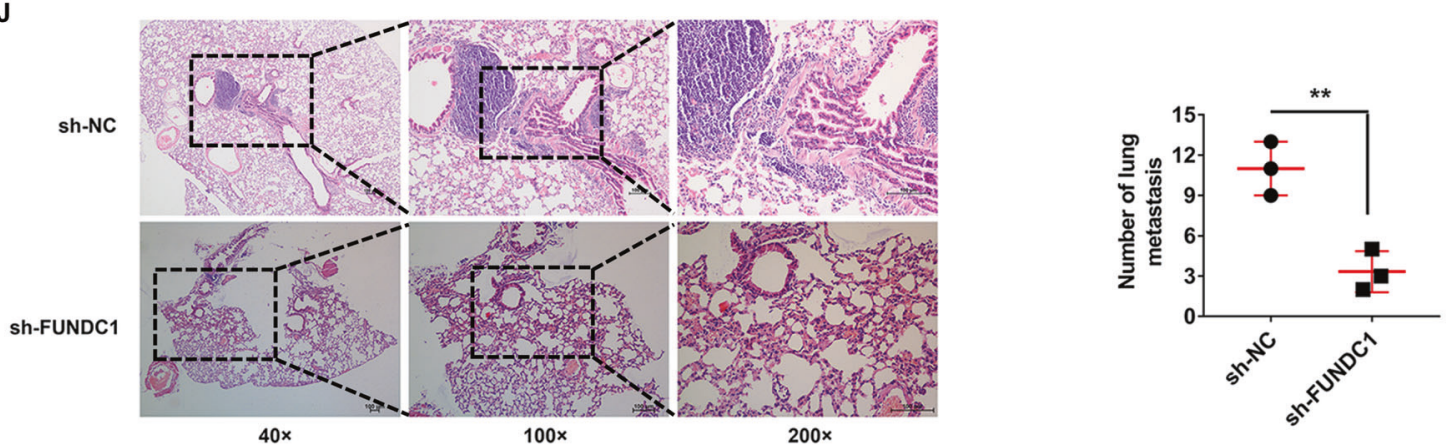

Fig. 1 FUNDC1 knockdown inhibited TNBC Progression. A 4T1, 891, and BT549 TNBC cells were treated with melatonin (10-1000 nM) or the vehicle for 48 or $96 \mathrm{~h}$. B Whole-genome mRNA expression microarray analyses were performed on melatonin-treated and melatoninuntreated 4T1 and 891 cells. C FUNDC1 was upregulated in TNBC tissues compared to normal tissues, according to the TCGA database. D The expression levels of FUNDC1 were determined in breast cancer cell lines by qRT-PCR. White: normal breast epithelial cell line; gray: non-TNBC cell line; black, TNBC cell line. E qRT-PCR showed that FUNDC1 knockdown was successful with sh-FUNDC1\#2. F A CCK-8 assay was performed after transfection in 4T1, 891, and BT549 TNBC cells. G A colony formation assay was performed (upper), and the results were quantified

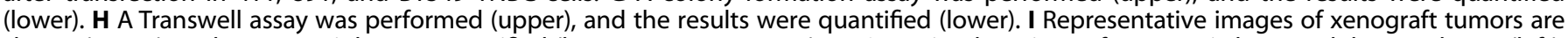
shown (upper), and tumor weight was quantified (lower, $n=3$ per group). J H\&E-stained sections of metastatic lung nodules are shown (left), and the number of metastatic nodules was quantified (right, $n=3$ per group). ${ }^{*} p<0.05,{ }^{* *} p<0.01$. 
A

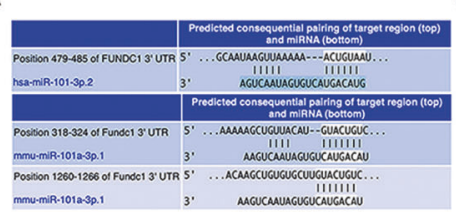

E

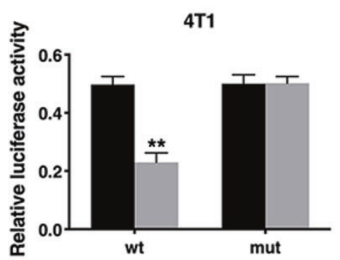

G

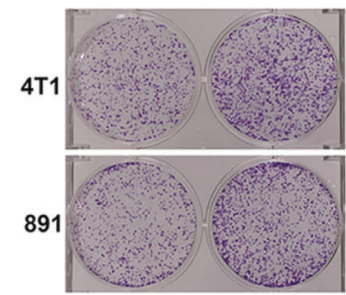

sh-FUNDC1 sh-FUNDC1

+LNA-NC +LNA-miR-101

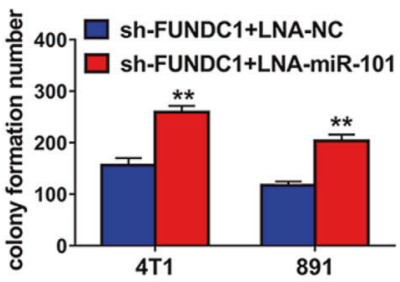

C

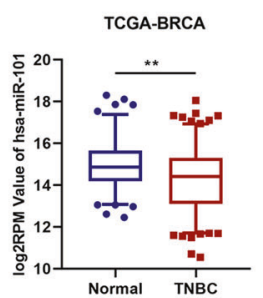

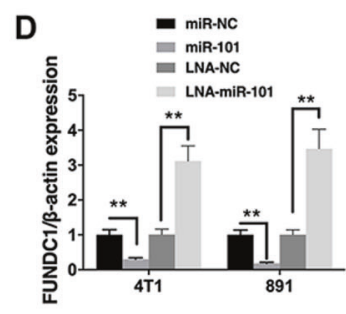

F sh-FUNDC1+LNA-NC

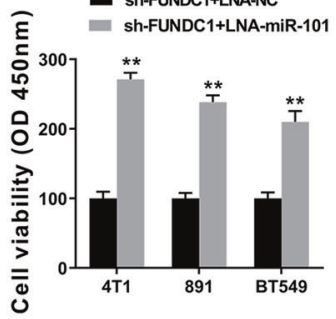

I
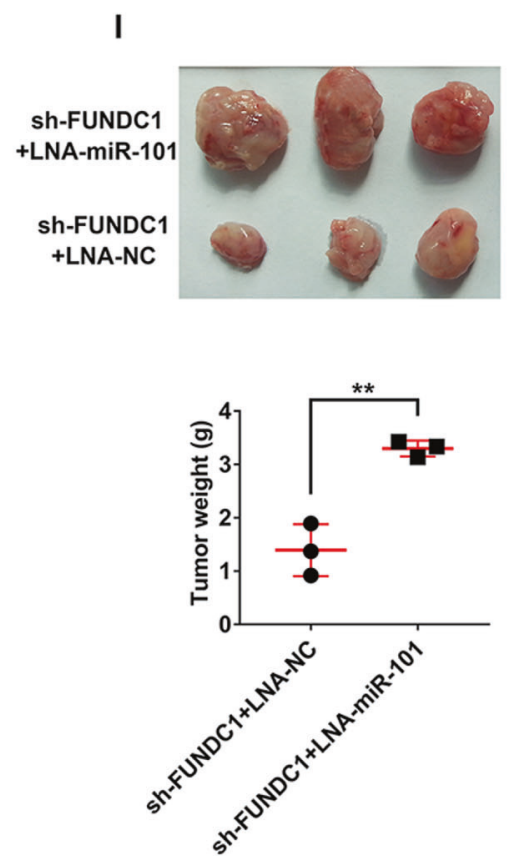

H

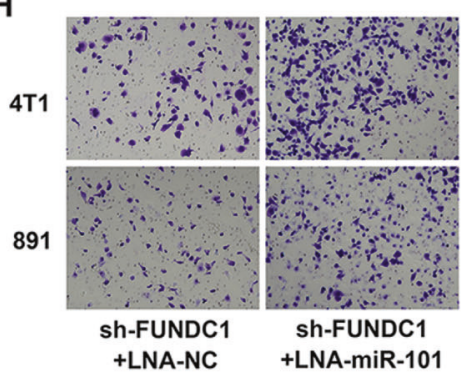

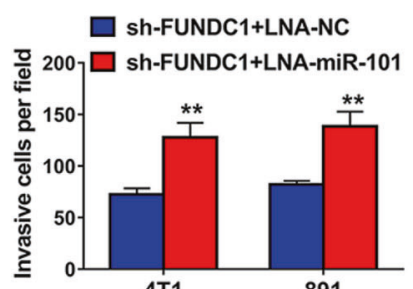

891

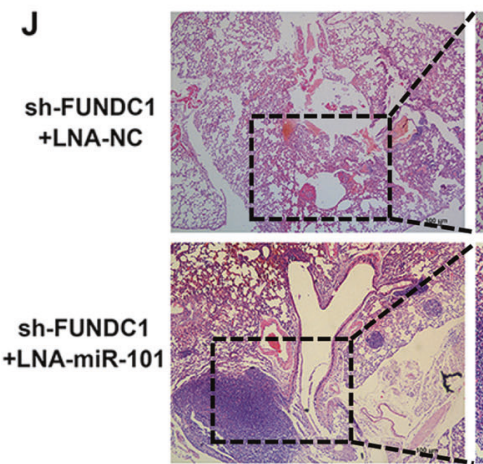

$40 x$

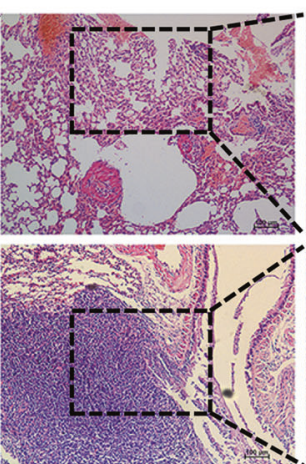

$100 x$
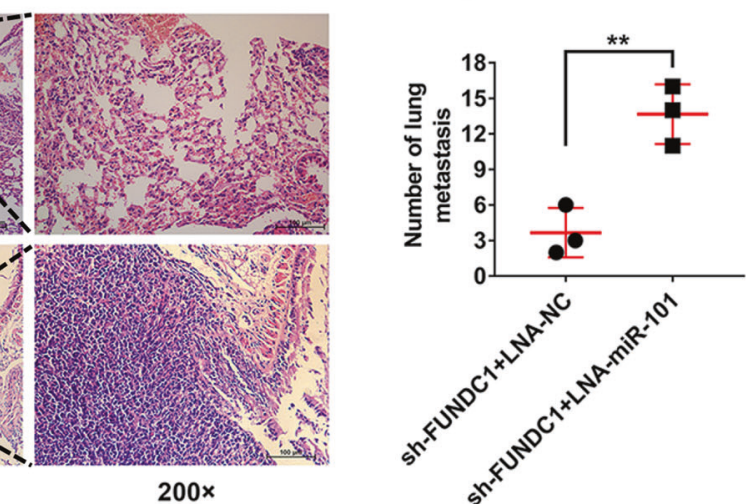

Fig. 2 FUNDC1 Is a Target Gene regulated by miR-101. A TargetScan showed the predicted binding sites of miR-101 within FUNDC1. B The expression of miR-101 was detected in breast cancer cell lines. White: normal breast epithelial cell line; gray: non-TNBC cell line; black, TNBC cell line. C hsa-miR-101 was downregulated in TNBC tissues compared to normal tissues, according to the TCGA database. D The expression level of FUNDC1 after transfection with the miR-101 mimic or LNA-miR-101 was determined by qRT-PCR. E Luciferase assay of cells transfected with vectors containing the FUNDC1 $3^{\prime}$ UTR (WT) or its mutant (mut). F A CCK-8 assay was performed after transfection in 4T1, 891, and BT549 TNBC cells. G A colony formation assay was performed (upper), and the results were quantified (lower). H A Transwell assay was performed (upper), and the results were quantified (lower). I Representative images of xenograft tumors were shown (upper), and tumor weight was quantified (lower, $n=3$ per group). J H\&E-stained sections of metastatic lung nodules were shown (left), and the number of metastatic nodules was quantified (right, $n=3$ per group). ${ }^{*} p<0.05,{ }^{* *} p<0.01$. 
A

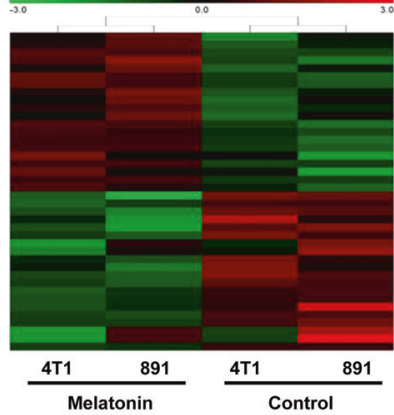

E
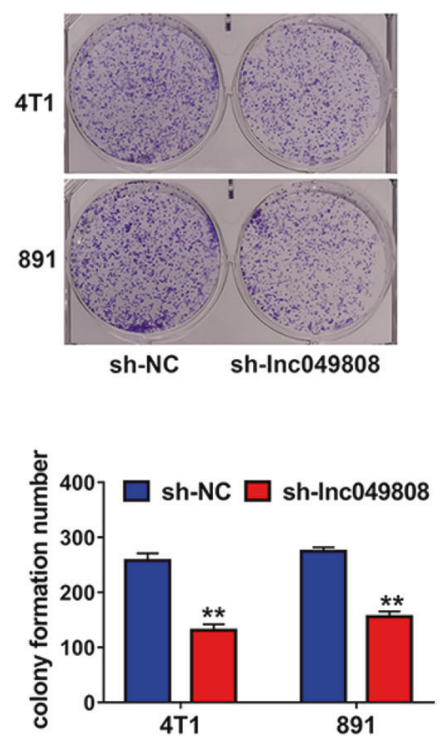

B

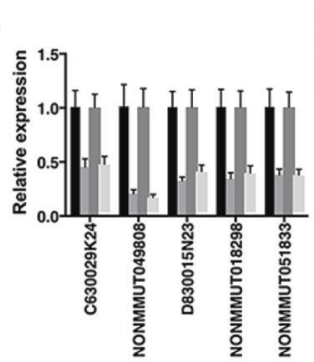

$\mathbf{F}$

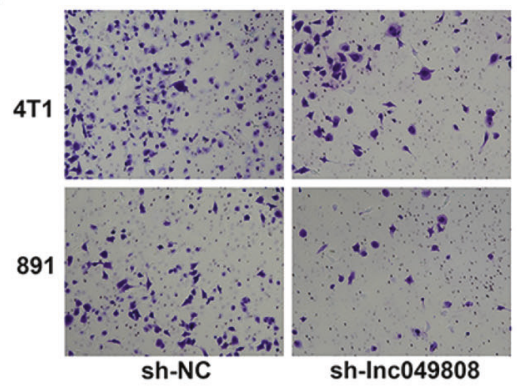

G
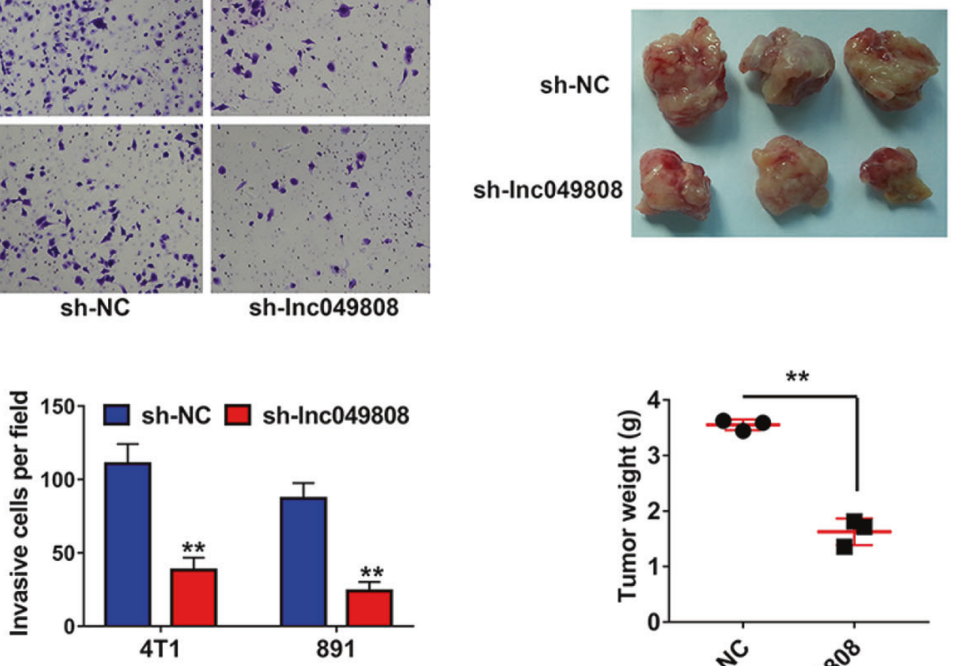

D $\widehat{\varepsilon}$

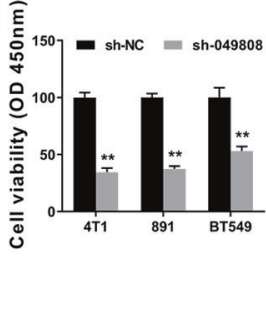

H
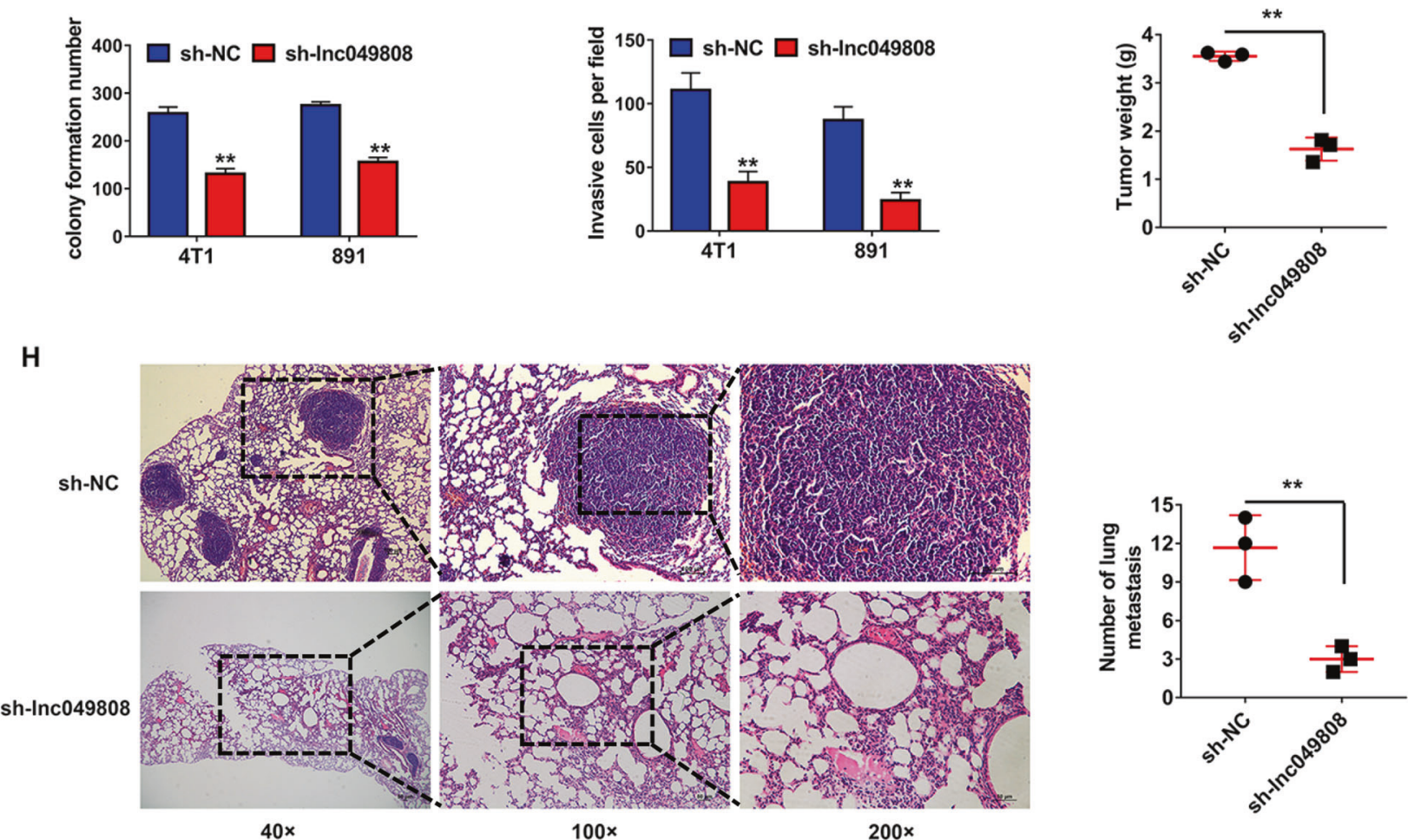

Fig. 3 Lnc049808 knockdown inhibited TNBC progression. A LncRNA microarray analyses were performed on 4T1 and 891 melatonintreated breast cancer cells. B The expression levels of the top five overlapping downregulated IncRNAs were determined by qRT-PCR. C qRTPCR showed that Inc049808 knockdown was successful with sh-049808\#1. D A CCK-8 assay was performed after transfection in 4T1, 891, and BT549 TNBC cells. E A colony formation assay was performed (upper), and the results were quantified (lower). F A Transwell assay was performed (upper), and the results were quantified (lower). G Representative images of xenograft tumors were shown (upper), and tumor weight was quantified (lower, $n=3$ per group). $\mathbf{H}$ H\&E-stained sections of metastatic lung nodules were shown (left), and the number of metastatic nodules was quantified (right, $n=3$ per group). ${ }^{*} p<0.05,{ }^{* *} p<0.01$.

TNBC cells, and the top 20 significantly differentially expressed genes and IncRNAs were identified. Among the downregulated mRNAs in melatonin-treated TNBC cells, we identified FUNDC1, which is a highly conserved mitochondrial outer membrane protein and plays an important role in mitochondrial autophagy [16]. Many factors can induce mitophagy, including hypoxia, DNA damage, inflammation, nutrient deprivation, and mitochondrial membrane depolarization. Dysfunction in mitophagy affects cell metabolism and differentiation, leading to multiple types of diseases, including Alzheimer's disease, heart failure, Parkinson's disease, and cancers [17-19]. Although a previous study proved that FUNDC1 regulates mitochondrial dynamics and mitophagy in mammalian cells, the expression status 
A

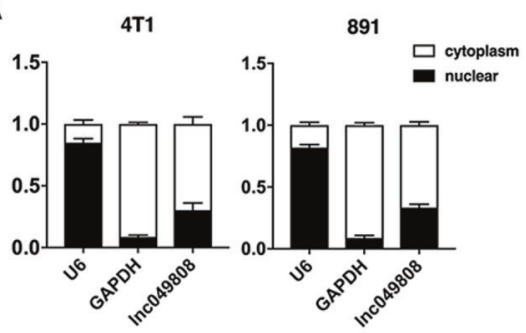

B

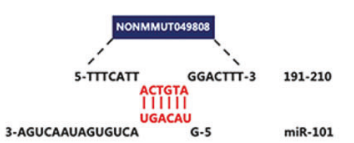

C

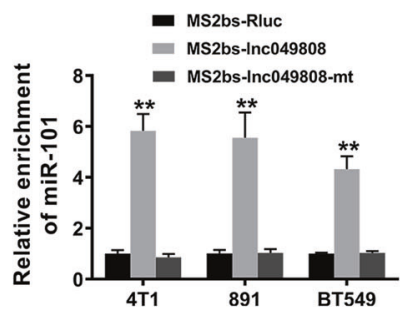

E
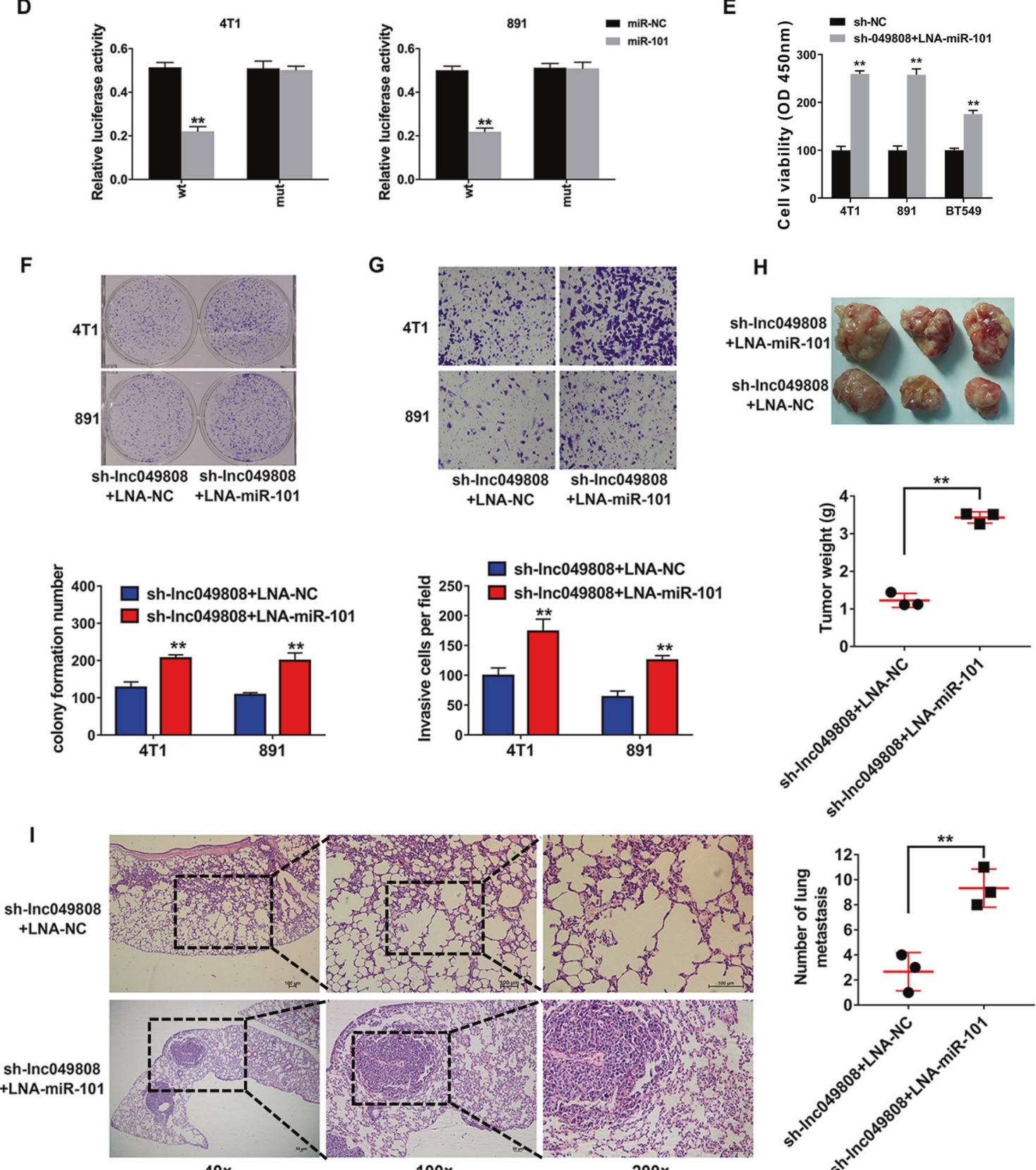

H

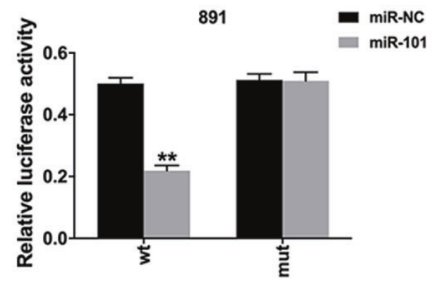

+LNA-NC
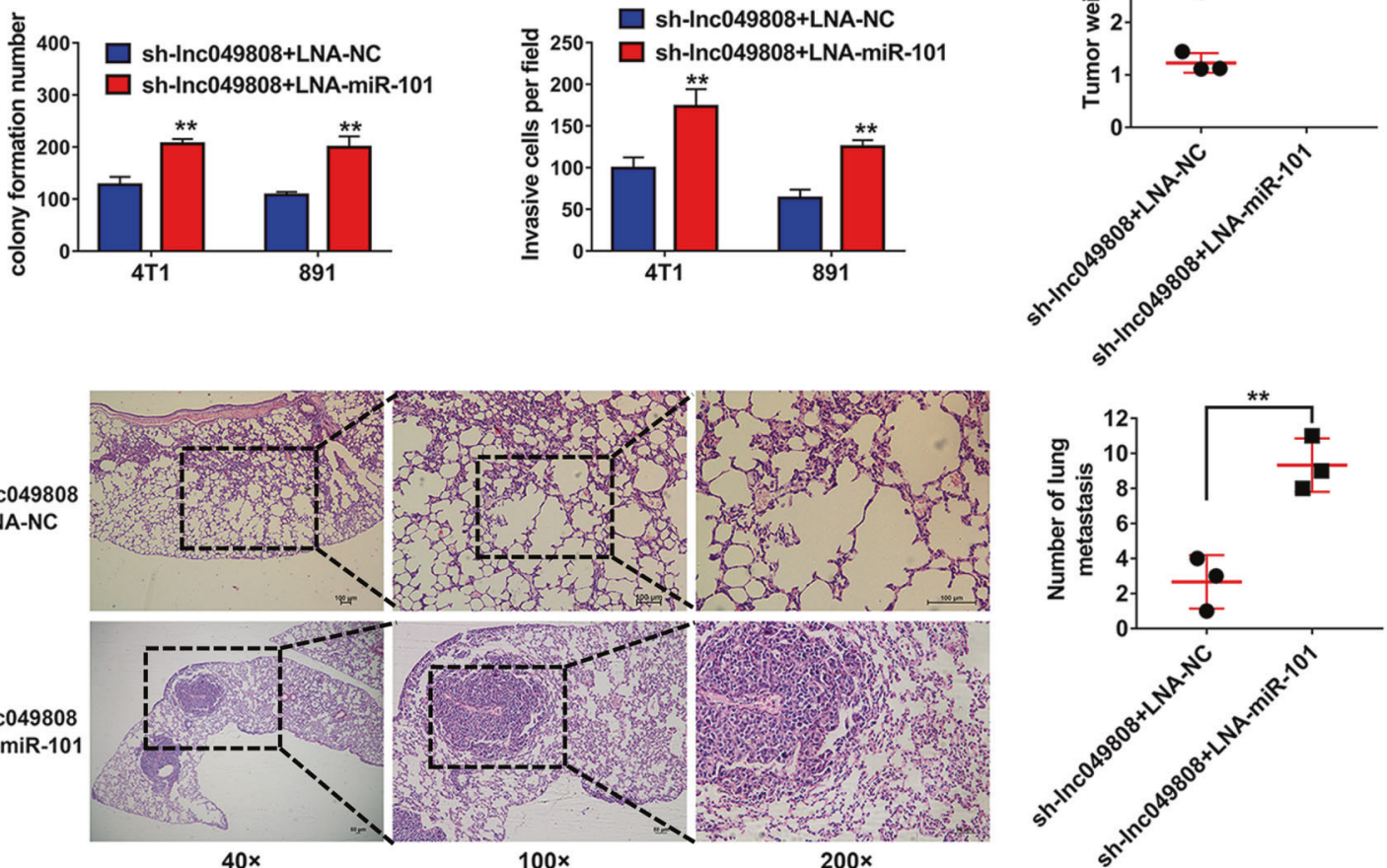

Fig. 4 Lnc049808 Is a target of miR-101. A U6, GAPDH, and Inc049808 levels were determined by qRT-PCR. B The predicted binding sites of miR-101 within Inc049808 are shown. C The MS2-based RIP assay confirmed the binding of miR-101 and Inc049808 in 4T1, 891, and BT549 TNBC cells. D Luciferase assay of cells transfected with vectors containing binding sites for miR-101 within Inc049808 (WT) or its mutant (mut). E CCK-8 assay was performed after transfection in 4T1, 891, and BT549 TNBC cells. F A colony formation assay was performed (upper), and the results were quantified (lower). G A Transwell assay was performed (upper), and the results were quantified (lower). H Representative images of xenograft tumors were shown (upper), and tumor weight was quantified (lower, $n=3$ per group). I H\&E-stained sections of metastatic lung nodules were shown (left), and the number of metastatic nodules was quantified (right, $n=3$ per group). ${ }^{*} p<0.05,{ }^{* *} p<0.01$. 
A

4T1
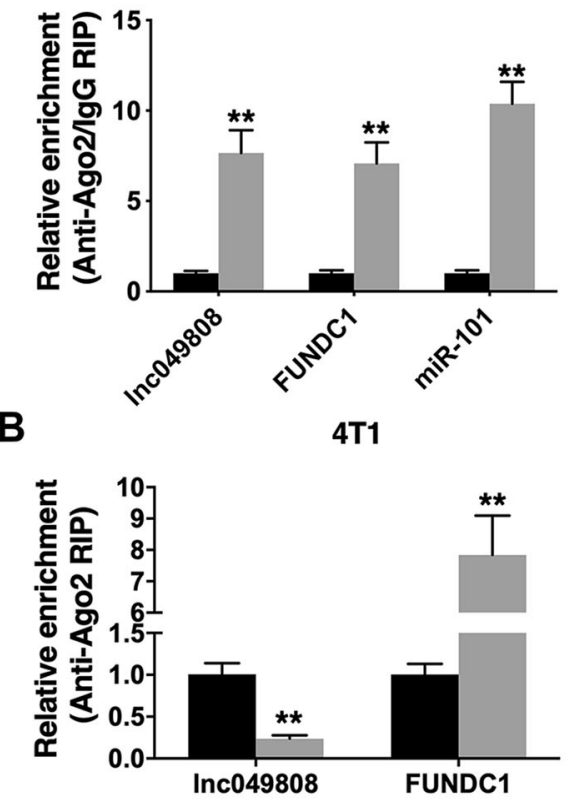

C

4T1
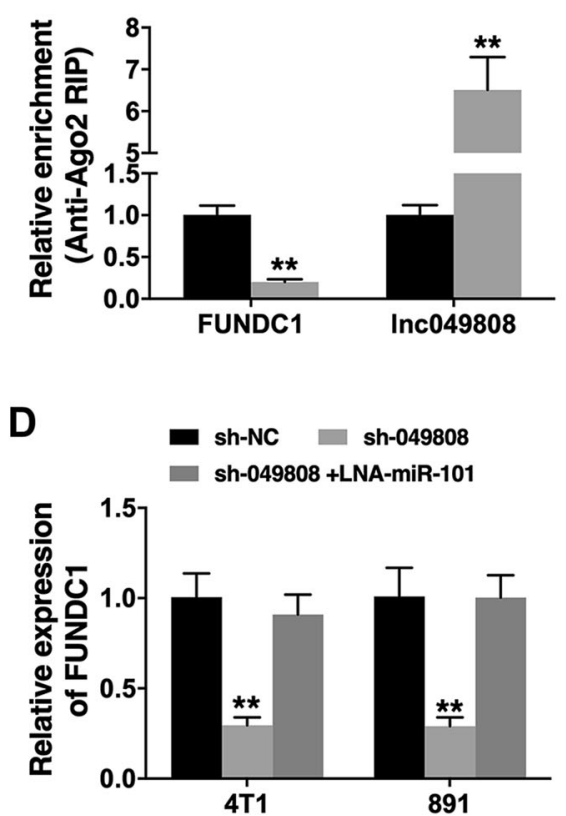

891
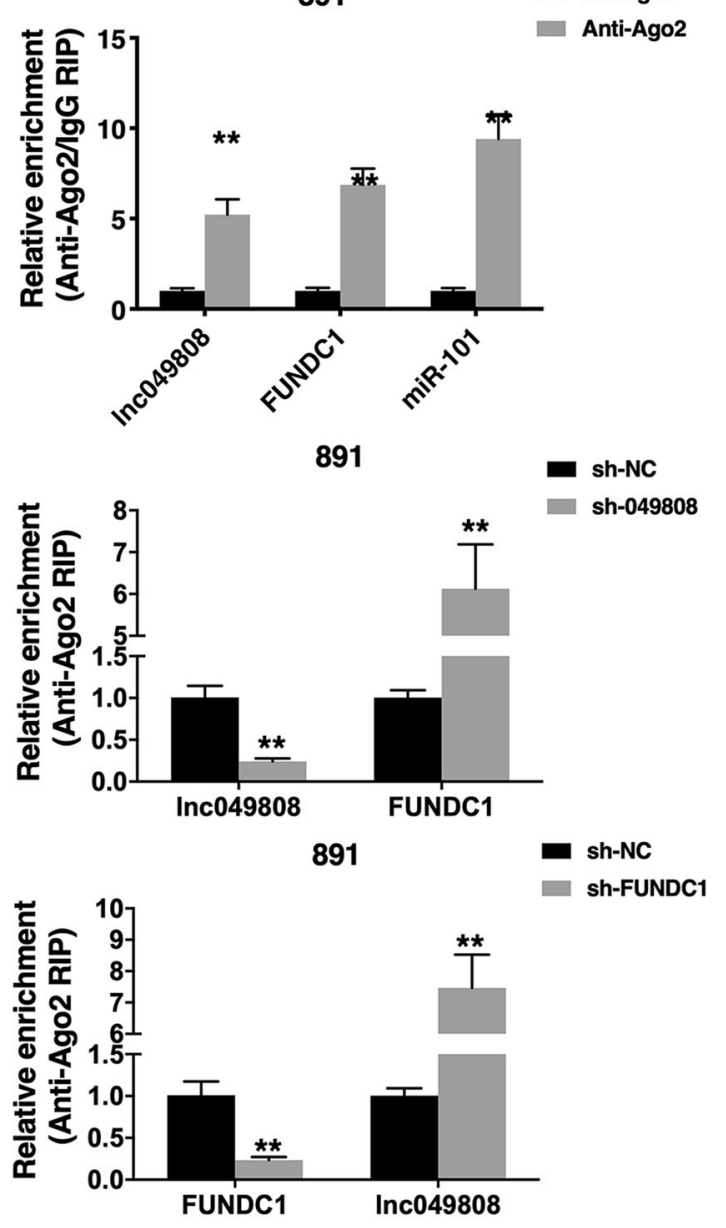

E

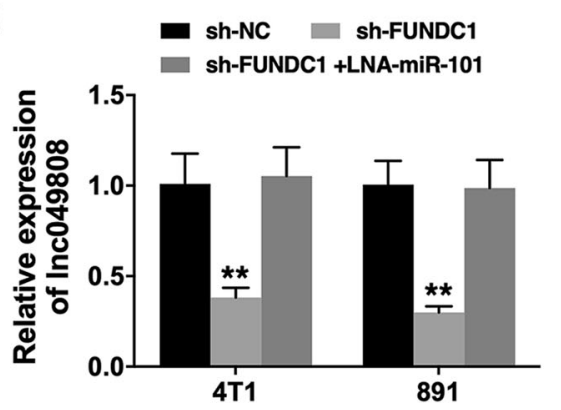

Fig. 5 Lnc049808 and FUNDC1 function as ceRNAs to regulate miR-101. A The RIP assay showed the enrichment of Lnc049808, FUNDC1, and miR-101 on Ago2 relative to IgG in 4T1 and 891 TNBC cells. B Ago2-related RIP assay was conducted after transfection with sh-049808 vector. C Ago2-related RIP assay was conducted after transfection with sh-FUNDC1 vector. Enrichment of FUNDC1 to Ago2 RNA binding protein was decreased after FUNDC1 suppression. D The FUNDC1 level was quantified after transfected with sh-049808 vector and/or LNAmiR-101. E Cells were transfected with sh-049808 vector and/or LNA-miR-101, and the Inc049808 level was determined by qRT-PCR. ${ }^{* *} p<0.01$.

and role of FUNDC1 in breast cancer are unclear. Here, we found that FUNDC1 upregulated in breast cancer cell lines and that knockdown of FUNDC1 suppressed breast cancer cell proliferation. Further exploration revealed that FUNDC1 was a target gene of miR-101 and that miR-101 regulated the expression and function of FUNDC1.

Recently, miR-101 has been proven to be a tumor suppressor in the initiation and progression of various malignancies [20]. Downregulation of miR-101 has been found in several malignancies, such as gastric cancer (GC) [21], hepatocellular carcinoma (HCC) [22], non-small-cell lung cancer (NSCLC) [23], cervical cancer [24], intrahepatic cholangiocarcinoma (ICC) [25], osteosarcoma
(OS) [26], oral squamous cell carcinoma (OSCC) [27], bladder transitional cell carcinoma (BTCC) [28], and intraductal papillary mucinous neoplasm of the pancreas (IPMN) [29]. In breast cancer, miR-101 has been reported to act as a suppressor of cell proliferation by decreasing the level of DNA methyltransferase 3A (DNMT3A) and targeting proteasome maturation protein (POMP) and Stathmin 1 (Stmn1) $[30,31]$. Our study showed that miR-101 inhibited TNBC progression by mediating FUNDC1, which confirmed the suppressive role of miR-101 in breast cancer.

Competing endogenous RNA (ceRNA) constitutes a microRNAmediated mechanism by which RNAs mediate each other by 
binding to shared miRNAs [32]. A variety of forms of RNAs, including pseudogenes, protein-coding transcripts, circular RNAs, and IncRNAs, can act as ceRNAs. Many IncRNAs have been demonstrated to function as ceRNAs [33-36]. Lnc-ceRNAs are important regulators of tissue development processes, including muscle differentiation [33], embryonic stem cell self-renewal, and cancer progression [35]. Though IncRNAs are expressed at low levels, their expression is more tissue-specific than that of proteincoding genes [37]. As the first proven Inc-ceRNA, the HULC was one of the most significantly upregulated transcripts in HCC [38]. In the current study, we performed IncRNA microarray analyses and found that Inc049808 was downregulated in melatonintreated breast cancer cells. Further investigation revealed that Inc049808 and FUNDC1 functioned as ceRNAs and competed for binding with miR-101 in the regulation of TNBC progression.

The antiproliferative effects of melatonin have been well studied in estrogen receptor a (ERa)-positive human breast cancer cell lines [39]. Previous studies revealed that melatonin suppresses ERa mRNA expression and ERa transcriptional activity via the MT1 receptor. However, the role of melatonin in ERa-negative cell lines is controversial. Mao et al. reported that the MDA-MB-231 human breast cancer cell line was unresponsive to melatonin's antiproliferative effect in vitro [40]. Kim et al. demonstrated that melatonin did not affect proliferation but suppressed the invasion and metastasis of MDA-MB-231 and HCC-70 human TNBC cells by promoting the production of KiSS1, a metastasis suppressor [41]. Ferreira et al. found that melatonin exerts its antitumor effects by reducing TNBC cell proliferation, migration, and c-Myc expression [42]. Woo et al. revealed that melatonin enhances tunicamycininduced apoptosis in human breast carcinoma MDA-MB-231 cells [43]. This contradictory effect may be attributed to the heterogeneity of TNBC. Studies have explored the expression of melatonin receptors (MRs) in TNBC in African-American and Caucasian women, finding that MRs are associated with survival and differentially expressed in these two populations [44]. In our study, we used three TNBC cell lines, BT549, 4T1, and 891, to confirm the role of melatonin and the underlying mechanisms. Our study confirmed the anticancer effect of melatonin on TNBC cells and found that melatonin inhibited TNBC progression through the Inc049808/miR-101/FUNDC1 axis, a ceRNA regulatory mechanism, which has never been reported.

FUNDC1, acting as an activator of hypoxia-induced mitophagy, is an important mechanism for mitochondrial quality control. It sustains oxidative bioenergetics, buffers ROS production, and supports cell proliferation. Li J et al. found the FUNDC1-LonP1 axis could control mitochondrial reprogramming and tumor cell plasticity through transforming between proliferative and invasive states. They demonstrated the role of FUNDC1 in prostate adenocarcinoma, glioblastoma, lung adenocarcinoma, and breast adenocarcinoma [45]. In addition, mitochondria are the core of innate immunity, and aberrant mitochondrial activity leads to immune activation and chronic inflammatory diseases, like cancers. FUNDC1-mediated mitophagy plays a crucial part in the inflammatory response and tumorigenesis [46]. The function of FUNDC1 that we discovered in this study is consistent with the report of $\mathrm{Wu} L$ et al., but we disclose for the first time its new mechanism as a ceRNA [47].

In conclusion, our findings indicated that melatonin inhibits TNBC progression via the Inc049808/miR-101/FUNDC1 axis and that melatonin may serve as an alternative therapy for TNBC.

\section{MATERIALS AND METHODS}

\section{Ethical approval declarations and consent to participate}

Approval for this study was obtained from the Ethics Committee of Sun Yat-Sen University Cancer Center Health Authority and was carried out according to the ethical standards of the Declaration of Helsinki. The IACUC of Sun Yat-Sen University Cancer Center approved all animal studies, which were performed according to its guidelines. The availability of data and information on the data set used and analyzed in the current study can be provided by the corresponding author upon request.

\section{Cell culture and transfection}

All cell lines used in this study were obtained from the American Type Culture Collection (USA). All cells were cultured according to the supplier's instructions and were confirmed to be free of mycoplasma contamination, as verified by DNA fingerprinting. Cells were transfected with Lipofectamine 2000 (Invitrogen, USA). shRNA sequences were synthesized by GeneCopoeia (Rockville, MD, USA) to target Lnc049808 and FUNDC1. A Lenti-Pac HIV Expression Packaging Kit (GeneCopoeia, Rockville, USA) was used to produce lentivirus expressing shRNAs. Puromycin $(2 \mathrm{mg} / \mathrm{mL})$ was adopted to select FUNDC1 and Lnc049808 knockdown cells. miR-101 mimics and inhibitors were purchased from GeneCopoeia.

\section{Microarray and cluster analysis}

The TNBC cell lines 4T1 and 891 were pretreated with melatonin $(100 \mathrm{nM}$; Sigma-Aldrich, USA) for $24 \mathrm{~h}$. Total RNA was extracted with TRlzol reagent (Life Technologies, USA). An Affymetrix GeneChip Mouse Genome 4302.0 Array and Agilent Mouse IncRNA Chip (CapitalBio Technology Corporation, China) were used for microarray analyses. GeneSpring software V. 13.0 (Agilent) was used for quantile normalization and data processing. Heatmaps were generated with Cluster 3.0 software.

\section{Quantitative RT-PCR analysis}

Total RNA was isolated with TRIzol (Invitrogen). The cytoplasmic and nuclear fractions were separated using a PARIS ${ }^{\text {TM }}$ kit (Invitrogen). qRT-PCR was carried out in a BioRad CFX96 PCR System (USA) with SYBR Premix Ex Taq II and PrimeScript RT Master Mix (Takara, Japan). The primers were synthesized by Invitrogen (Table S1). An All-in-One miRNA qRT-PCR Detection Kit (GeneCopoeia) was used for qRT-PCR of miRNA. The $2^{-\Delta \Delta C t}$ method was used to normalize the threshold cycle $(\mathrm{Ct})$ values to those of $\beta$-actin or $\mathrm{U6}$.

\section{CCK-8 and colony formation assays}

Transfected cells $\left(1 \times 10^{3}\right)$ were seeded into 96-well plates for 2 days, and then $10 \mathrm{ml} / \mathrm{\mu l}$ CCK-8 solutions (Dojindo Laboratories, Japan) were added to each well. The absorbance at $450 \mathrm{nM}$ was measured after $2 \mathrm{~h}$ of incubation at $37^{\circ} \mathrm{C}$. After 2 weeks of incubation at $37^{\circ} \mathrm{C}$, cells $\left(1 \times 10^{3}\right)$ were seeded in six-well plates for colony formation assays. The cell colonies were fixed with methanol and stained with $0.1 \%$ crystal violet, and colonies in each well were imaged and counted immediately.

\section{Transwell assay}

A total of $1 \times 10^{4}$ cells were seeded in each well of migration chambers (BD Biosciences, USA), and a chemotactic agent (10\% FBS medium) was added to the lower section of the chambers. After $24 \mathrm{~h}$, the cell colonies were fixed with methanol and stained with $0.1 \%$ crystal violet, and colonies were counted immediately.

\section{Mouse xenograft model}

A total of $2 \times 10^{6} 4 \mathrm{~T} 1$ cells were subcutaneously injected into the dorsal flanks of 4-week-old female BALB/c nude mice (3 mice per group). After 4 weeks, xenografts were harvested under anesthesia, and tumors were weighed and recorded. For the lung metastasis experiment, $1 \times 10^{5} 4 \mathrm{~T} 1$ cells were injected via the tail vein ( 3 mice per group). After eight weeks, the mice were euthanized, and the lungs were harvested. Macroscopically visible metastatic nodules were counted and subsequently confirmed by hematoxylin and eosin (H\&E) staining.

\section{Luciferase reporter assay}

The FUNDC1 $3^{\prime}$-UTR or Lnc049808 sequence (including the miR-101 binding site) was inserted into the pGL3 luciferase vector (Promega, USA) to construct the luciferase reporter vector. A rapid site-directed mutagenesis kit (TIANGEN, China) was used to generate mutations in the seed region of miR-101 as a mutation control. A dual-luciferase reporter gene assay system (Promega) was used to measure luciferase activity.

\section{RIP assay}

Cells were cotransfected with MS2bs-Lnc049808, MS2bs-049808-mt, or MS2bs-Rluc, and MS2bp-GFP. After $48 \mathrm{~h}$, a Magna RIP RNA-Binding Protein Immunoprecipitation Kit (Millipore) was used to conduct RIP. The level of miR-101 was measured after the RNA complexes were purified. The Ago2 
RIP assay was performed using an anti-Ago2 antibody (Millipore), and the levels of Inc049808, FUNDC1, and miR-101 were further measured.

\section{Statistical analysis}

All data were analyzed with SPSS 19.0 software. We used $t$-tests and Pearson $X^{2}$ tests to compare the differences between groups. Unless otherwise stated, the data are expressed as the mean \pm standard deviation of three independent experiments. $p<0.05$ was considered statistically significant.

\section{DATA AVAILABILITY}

The availability of data and information on the data set used and analyzed in the current study would be provided by the corresponding author upon request.

\section{REFERENCES}

1. Carey L, Winer E, Viale G, Cameron D, Gianni L. Triple-negative breast cancer: disease entity or title of convenience? Nat Rev Clin Oncol. 2010;7:683-92.

2. Slominski AT, Hardeland R, Zmijewski MA, Slominski RM, Reiter RJ, Paus R. Melatonin: a cutaneous perspective on its production, metabolism, and functions. J Invest Dermatol. 2018;138:490-9.

3. Acuna-Castroviejo D, Escames G, Venegas C, Diaz-Casado ME, Lima-Cabello E, Lopez LC, et al. Extrapineal melatonin: sources, regulation, and potential functions. Cell Mol Life Sci. 2014;71:2997-3025.

4. Bonnefont-Rousselot D, Collin F. Melatonin: action as antioxidant and potential applications in human disease and aging. Toxicology. 2010;278:55-67.

5. Reiter RJ, Tan DX, Fuentes-Broto L. Melatonin: a multitasking molecule. Prog Brain Res. 2010;181:127-51.

6. Miller SC, Pandi-Perumal SR, Esquifino Al, Cardinali DP, Maestroni GJ. The role of melatonin in immuno-enhancement: potential application in cancer. Int J Exp Pathol. 2006;87:81-87.

7. Nooshinfar E, Safaroghli-Azar A, Bashash D, Akbari ME. Melatonin, an inhibitory agent in breast cancer. Breast Cancer. 2017;24:42-51.

8. Proietti S, Catizone A, Masiello MG, Dinicola S, Fabrizi G, Minini M, et al. Increase in motility and invasiveness of MCF7 cancer cells induced by nicotine is abolished by melatonin through inhibition of ERK phosphorylation. J Pineal Res. 2018;64: e12467.

9. Lu KH, Su SC, Lin CW, Hsieh YH, Lin YC, Chien MH, et al. Melatonin attenuates osteosarcoma cell invasion by suppression of C-C motif chemokine ligand 24 through inhibition of the c-Jun N-terminal kinase pathway. J Pineal Res. 2018;65: e12507.

10. Lee $\mathrm{H}$, Lee $\mathrm{HJ}$, Jung $\mathrm{JH}$, Shin EA, Kim SH. Melatonin disturbs SUMOylationmediated crosstalk between c-Myc and nestin via MT1 activation and promotes the sensitivity of paclitaxel in brain cancer stem cells. J Pineal Res. 2018;65: e12496.

11. Mao L, Yuan L, Slakey LM, Jones FE, Burow ME, Hill SM. Inhibition of breast cancer cell invasion by melatonin is mediated through regulation of the p38 mitogen-activated protein kinase signaling pathway. Breast Cancer Res. 2010;12: R107.

12. Xiang S, Dauchy RT, Hauch A, Mao L, Yuan L, Wren MA, et al. Doxorubicin resistance in breast cancer is driven by light at night-induced disruption of the circadian melatonin signal. J Pineal Res. 2015;59:60-69.

13. Zhang J, Bai R, Li M, Ye H, Wu C, Wang C, et al. Excessive miR-25-3p maturation via $\mathrm{N}(6)$-methyladenosine stimulated by cigarette smoke promotes pancreatic cancer progression. Nat Commun. 2019;10:1858.

14. Tan L, Mai D, Zhang B, Jiang X, Zhang J, Bai R, et al. PIWl-interacting RNA-36712 restrains breast cancer progression and chemoresistance by interaction with SEPW1 pseudogene SEPW1P RNA. Mol Cancer. 2019;18:9.

15. Mai D, Ding P, Tan L, Zhang J, Pan Z, Bai R, et al. PIWl-interacting RNA-54265 is oncogenic and a potential therapeutic target in colorectal adenocarcinoma. Theranostics. 2018;8:5213-30.

16. Liu L, Feng $D$, Chen $G$, Chen $M$, Zheng $Q$, Song $P$, et al. Mitochondrial outermembrane protein FUNDC1 mediates hypoxia-induced mitophagy in mammalian cells. Nat Cell Biol. 2012;14:177-85.

17. Palikaras K, Tavernarakis N. Mitophagy in neurodegeneration and aging. Front Genet. 2012;3:297.

18. Taylor R, Goldman SJ. Mitophagy and disease: new avenues for pharmacological intervention. Curr Pharm Des. 2011;17:2056-73.

19. Chan DC. Mitochondria: dynamic organelles in disease, aging, and development Cell. 2006;125:1241-52.

20. Mourelatos Z, Dostie J, Paushkin S, Sharma A, Charroux B, Abel L, et al. miRNPs: a novel class of ribonucleoproteins containing numerous microRNAs. Genes Dev. 2002;16:720-8.
21. Wang HJ, Ruan HJ, He XJ, Ma YY, Jiang XT, Xia YJ, et al. MicroRNA-101 is downregulated in gastric cancer and involved in cell migration and invasion. Eur J Cancer. 2010;46:2295-303.

22. Li S, Fu H, Wang Y, Tie $\mathrm{Y}$, Xing R, Zhu J, et al. MicroRNA-101 regulates expression of the $v$-fos FBJ murine osteosarcoma viral oncogene homolog (FOS) oncogene in human hepatocellular carcinoma. Hepatology. 2009;49:1194-202.

23. Suzuki M, Cao K, Kato S, Komizu Y, Mizutani N, Tanaka K, et al. Targeting ceramide synthase 6-dependent metastasis-prone phenotype in lung cancer cells. J Clin Invest. 2016;126:254-65.

24. Lin C, Huang F, Shen G, Yiming A. MicroRNA-101 regulates the viability and invasion of cervical cancer cells. Int J Clin Exp Pathol. 2015;8:10148-55.

25. Deng G, Teng Y, Huang F, Nie W, Zhu L, Huang W, et al. MicroRNA-101 inhibits the migration and invasion of intrahepatic cholangiocarcinoma cells via direct suppression of vascular endothelial growth factor-C. Mol Med Rep. 2015;12:7079-85.

26. Wang Z, He R, Xia H, Wei YU, Wu S. MicroRNA-101 has a suppressive role in osteosarcoma cells through the targeting of c-FOS. Exp Ther Med. 2016;11:1293-9.

27. Wu B, Lei D, Wang L, Yang X, Jia S, Yang Z, et al. MiRNA-101 inhibits oral squamous-cell carcinoma growth and metastasis by targeting zinc finger E-box binding homeobox 1. Am J Cancer Res. 2016;6:1396-407.

28. Friedman JM, Liang G, Liu CC, Wolff EM, Tsai YC, Ye W, et al. The putative tumor suppressor microRNA-101 modulates the cancer epigenome by repressing the polycomb group protein EZH2. Cancer Res. 2009;69:2623-9.

29. Nakahara O, Takamori H, Iwatsuki M, Baba $Y$, Sakamoto $Y$, Tanaka H, et al. Carcinogenesis of intraductal papillary mucinous neoplasm of the pancreas: loss of microRNA-101 promotes overexpression of histone methyltransferase EZH2. Ann. Surg. Oncol. 2012;19:S565-571.

30. Zhang X, Schulz R, Edmunds S, Kruger E, Markert E, Gaedcke J, et al. MicroRNA101 suppresses tumor cell proliferation by acting as an endogenous proteasome inhibitor via targeting the proteasome assembly factor POMP. Mol Cell. 2015;59:243-57.

31. Wang R, Wang HB, Hao CJ, Cui Y, Han XC, Hu Y, et al. MiR-101 is involved in human breast carcinogenesis by targeting Stathmin1. PLoS ONE. 2012;7:e46173.

32. Karreth FA, Tay $Y$, Perna D, Ala U, Tan SM, Rust AG, et al. In vivo identification of tumor-suppressive PTEN ceRNAs in an oncogenic BRAF-induced mouse model of melanoma. Cell. 2011;147:382-95.

33. Cesana M, Cacchiarelli D, Legnini I, Santini T, Sthandier O, Chinappi M, et al. A long noncoding RNA controls muscle differentiation by functioning as a competing endogenous RNA. Cell. 2011;147:358-69.

34. Yoon JH, Abdelmohsen $\mathrm{K}$, Srikantan S, Yang X, Martindale JL, De S, et al. LincRNAp21 suppresses target mRNA translation. Mol Cell. 2012;47:648-55.

35. Wang $Y, X u$ Z, Jiang J, Xu C, Kang J, Xiao L, et al. Endogenous miRNA sponge lincRNA-RoR regulates Oct4, Nanog, and Sox2 in human embryonic stem cell selfrenewal. Dev Cell. 2013;25:69-80.

36. Du Z, Sun T, Hacisuleyman E, Fei T, Wang X, Brown M, et al. Integrative analyses reveal a long noncoding RNA-mediated sponge regulatory network in prostate cancer. Nat Commun. 2016;7:10982.

37. Guttman M, Rinn JL. Modular regulatory principles of large non-coding RNAs. Nature. 2012;482:339-46.

38. Wang J, Liu X, Wu H, Ni P, Gu Z, Qiao Y, et al. CREB up-regulates long non-coding RNA, HULC expression through interaction with microRNA-372 in liver cancer. Nucleic Acids Res. 2010;38:5366-83.

39. Ram PT, Kiefer T, Silverman M, Song Y, Brown GM, Hill SM. Estrogen receptor transactivation in MCF-7 breast cancer cells by melatonin and growth factors. Mol Cell Endocrinol. 1998;141:53-64.

40. Mao L, Yuan L, Xiang S, Zeringue SB, Dauchy RT, Blask DE, et al. Molecular deficiency (ies) in MT(1) melatonin signaling pathway underlies the melatoninunresponsive phenotype in MDA-MB-231 human breast cancer cells. J Pineal Res. 2014;56:246-53.

41. Kim TH, Cho SG. Melatonin-induced KiSS1 expression inhibits triple-negative breast cancer cell invasiveness. Oncol Lett. 2017;14:2511-6.

42. Ferreira LC, Orso F, Dettori D, Lacerda JZ, Borin TF, Taverna D, et al. The role of melatonin on miRNAs modulation in triple-negative breast cancer cells. PLoS ONE. 2020;15:e0228062.

43. Woo SM, Min KJ, Kwon TK. Melatonin-mediated Bim up-regulation and cyclooxygenase-2 (COX-2) down-regulation enhances tunicamycin-induced apoptosis in MDA-MB-231 cells. J Pineal Res. 2015;58:310-20.

44. Oprea-llies G, Haus E, Sackett-Lundeen L, Liu Y, McLendon L, Busch R, et al. Expression of melatonin receptors in triple negative breast cancer (TNBC) in African American and Caucasian women: relation to survival. Breast Cancer Res Treat. 2013;137:677-87

45. Li J, Agarwal E, Bertolini I, Seo JH, Caino MC, Ghosh JC, et al. The mitophagy effector FUNDC1 controls mitochondrial reprogramming and cellular plasticity in cancer cells. Sci Signal. 2020;13:eaaz8240. 
10

46. Li W, Li Y, Siraj S, Jin H, Fan Y, Yang X, et al. FUN14 domain-containing 1-mediated mitophagy suppresses hepatocarcinogenesis by inhibition of inflammasome activation in mice. Hepatology. 2019;69:604-21.

47. Wu L, Zhang D, Zhou L, Pei Y, Zhuang Y, Cui W, et al. FUN14 domain-containing 1 promotes breast cancer proliferation and migration by activating calciumNFATC1-BMI1 axis. EBioMedicine. 2019;41:384-94.

\section{AUTHOR CONTRIBUTIONS}

$\mathrm{FP}, \mathrm{CP}, \mathrm{PL}$, and $\mathrm{YK}$ designed the study. $\mathrm{FP}, \mathrm{AY}, \mathrm{LZ}, \mathrm{LX}, \mathrm{SO}, \mathrm{ZH}, \mathrm{SW}, \mathrm{CP}, \mathrm{PL}$, and $\mathrm{YK}$ performed the in vitro and animal experiments. $A Y, L Z, L X, S O, Z H, S W$, and $Y K$ analyzed the data. $\mathrm{YK}, \mathrm{FP}, \mathrm{CP}, \mathrm{PL}$, and $\mathrm{AY}$ and wrote the paper. All authors read and approved the final paper.

\section{FUNDING}

This work was supported by grants from the Province Natural Science Foundation of Guangdong (2020A1515010285, 2021A1515010547, PL; 2020A1515110034, AY) and the Guangzhou Foundation and Application Foundation Fund (202102020175, YK).

\section{ETHICS APPROVAL AND CONSENT TO PARTICIPATE}

Approval for this study was obtained from the Ethics Committee of Sun Yat-Sen University Cancer Center Health Authority and was carried out according to the ethical standards of the Declaration of Helsinki. The IACUC of Sun Yat-Sen University Cancer Center approved all animal studies, which were performed according to its guidelines.

\section{COMPETING INTERESTS}

The authors declare no competing interests.

\section{ADDITIONAL INFORMATION}

Supplementary information The online version contains supplementary material available at https://doi.org/10.1038/s41419-021-04006-x.

Correspondence and requests for materials should be addressed to C.P., P.L. or Y.K.

Reprints and permission information is available at http://www.nature.com/ reprints

Publisher's note Springer Nature remains neutral with regard to jurisdictional claims in published maps and institutional affiliations.
Open Access This article is licensed under a Creative Commons Attribution 4.0 International License, which permits use, sharing, adaptation, distribution and reproduction in any medium or format, as long as you give appropriate credit to the original author(s) and the source, provide a link to the Creative Commons license, and indicate if changes were made. The images or other third party material in this article are included in the article's Creative Commons license, unless indicated otherwise in a credit line to the material. If material is not included in the article's Creative Commons license and your intended use is not permitted by statutory regulation or exceeds the permitted use, you will need to obtain permission directly from the copyright holder. To view a copy of this license, visit http://creativecommons. org/licenses/by/4.0/.

(c) The Author(s) 2021 